\title{
Intergrowth Structures in Synthetic Pyrochlores: Implications for Radiation Damage Effects and Waste Form Formulation*
}

\author{
E. C. Buck, D. B. Chamberlain, and R. Gieré \\ Chemical Technology Division \\ Argonne National Laboratory \\ 9700 South Cass Avenue \\ Argonne II 60439-4837 \\ TDepartment of Earth and Atmospheric Sciences \\ University of Purdue \\ Indiana
}

The submitted manuscript has been authored by
a contractor of the U.S. Government under
contract No. W-31-109-ENG-38. Accordingly,
the U.S. Government retains a nonexclusive,
royalty-free license to publish or reproduce the
published form of this contribution, or allow
others to do so, for U.S. Government purposes.

Submitted for consideration in

\section{Scientific Basis for Nuclear Waste Management XXII \\ Boston, MA \\ November 1998}

\footnotetext{
* This work was performed under guidance of the DOS Fissile Materials Disposition Progam (FMD). Work supported by the U.S. Department of Energy under contract W-31-109-ENG-38.
} 


\section{DISCLAIMER}

This report was prepared as an account of work sponsored by an agency of the United States Government. Neither the United States Government nor any agency thereof, nor any of their employees, make any warranty, express or implied, or assumes any legal liability or responsibility for the accuracy, completeness, or usefulness of any information, apparatus, product, or process disclosed, or represents that its use would not infringe privately owned rights. Reference herein to any specific commercial product, process, or service by trade name, trademark, manufacturer, or otherwise does not necessarily constitute or imply its endorsement, recommendation, or favoring by the United States Government or any agency thereof. The views and opinions of authors expressed herein do not necessarily state or reflect those of the United States Government or any agency thereof. 


\section{DISCLAIMER}

Portions of this document may be illegible in electronic image products. Images are produced from the best available original document. 


\title{
INTERGROWTH STRUCTURES IN SYNTHETIC PYROCHLORES: IMPLICATIONS FOR RADIATION DAMAGE EFFECTS AND WASTE FORM FORMULATION
}

\author{
E. C. BUCK, D. B. CHAMBERLAIN, AND R. GIERÉ*
}

Chemical Technology Division, Argonne National Laboratory, Argonne, IL 60439, *Department of Earth and Atmospheric Sciences, Purdue University, West Lafayette, IN 47907-1397

\begin{abstract}
Titanate-based ceramic waste forms are currently under development for the immobilization of excess weapons plutonium. Both Hf and Gd are added to the ceramic formulation as neutron absorbers in order to satisfy a defense-in-depth concept for the waste form. The introduction of significant amounts of hafnium may be responsible for the presence of zirconolite-2M crystals in pyrochlore-based ceramics and the formation of zirconolite lamellae within pyrochlore. The zirconolite grows epitaxially on $\{111\}$ planes of pyrochlore. Although the zirconolite lamellae within pyrochlore are non-cubic, any volume expansion due to radiation damage in the pyrochlore should still be isotropic; in addition, the presence of these intergrowths may allow some stress relief in the ceramic.
\end{abstract}

\section{INTRODUCTION}

Titanate-based ceramic waste forms are currently under development for the immobilization of excess weapons plutonium [1]. These ceramics exhibit excellent durability at various physical and chemical conditions [2]. The major phases in these ceramics are pyrochlore $\left[\mathrm{A}_{2} \mathrm{Ti}_{2} \mathrm{O}_{7}\right]$, zirconolite $\left[\mathrm{ABTi}_{2} \mathrm{O}_{7}\right]$, Hf-bearing rutile $\left(\mathrm{TiO}_{2}\right)$, and brannerite $\left[\mathrm{BTi}{ }_{2} \mathrm{O}_{6}\right]$, where $\mathrm{A}=\mathrm{Ca}$, actinides $(\mathrm{ACT})$, and rare earth elements $(\mathrm{REE})$, and $\mathrm{B}=\mathrm{ACT}, \mathrm{REE}, \mathrm{Zr}$, and Hf. Additional minor phases may occur depending on waste loading; these include uranium oxides and glassy phases. The glassy phases (and rutile) fill interstices between the major phases. Both $\mathrm{Hf}$ and $\mathrm{Gd}$ are added to the ceramic formulation as neutron absorbers in order to satisfy a defense-in-depth concept for the waste form. Although the capacity of Gd to stop thermal (low energy) neutrons is nearly 500 times greater than that of $\mathrm{Hf}$, the capacity of $\mathrm{Hf}$ to absorb thermal and epithermal (medium energy) neutrons is still far greater than any other major element in the ceramic besides $\mathrm{Gd}$ [3]. However, the main reason for adding $\mathrm{Hf}$ is that it possesses a much lower aqueous solubility than $\mathrm{Gd}[4]$; therefore, $\mathrm{Hf}$ should be present in any residual $\mathrm{Pu}$ precipitate that may form during possible ceramic corrosion [2].

In this study, a series of plutonium-free ceramic formulations containing various levels of impurities was investigated. In this paper, a particular microstructural feature is described in three formulations: the baseline composition, which contains only $\mathrm{Ca}, \mathrm{Ti}, \mathrm{U}$, $\mathrm{Ce}, \mathrm{Gd}$, and $\mathrm{Hf}$, and two impurity samples. The levels of impurities in these samples are based on anticipated waste streams to be received during the fabrication of the $\mathrm{Pu}$ ceramic. The two impurity ceramics examined were a metallic-based impurity sample containing small amounts of transition metals and an extreme oxide impurity sample, which contained $\mathrm{Si}, \mathrm{Al}, \mathrm{Mg}, \mathrm{Na}$, and $\mathrm{Ga}$, as well as a range of transition metal oxides.

\section{EXPERIMENTAL PROCEDURE}

The ceramic material was prepared at Lawrence Livermore National Laboratory (LLNL) by blending the following: $\mathrm{TiO}_{2}$ (anatase), $\mathrm{UO}_{2}, \mathrm{Gd}_{2} \mathrm{O}_{3}, \mathrm{Ca}(\mathrm{OH})_{2}, \mathrm{HfO}_{2}$, and $\mathrm{CeO}_{2}$ for $1 \mathrm{~h}$ at $750^{\circ} \mathrm{C}$ in air. This mixture was pressed at $83 \mathrm{MPa}$ and then sintered for $4 \mathrm{~h}$ in $\mathrm{Ar}$ at $1350^{\circ} \mathrm{C}$. The cool-down rate was $\approx 5 \% \mathrm{~min}$. For the impurity samples, other 
compounds were added during the initial blending step. The compositions of these ceramics are listed elsewhere in these proceedings [2]. The major titanate phase in these samples was pyrochlore with lesser amounts of brannerite, zirconolite, and rutile. Depending on the impurities added, other phases were observed. The samples were examined with scanning electron microscopy (SEM), electron microprobe analysis (EMPA), and analytical transmission electron microscopy (AEM).

For the transmission electron microscopy (TEM), the ceramic material was crushed between two clean glass slides. A small amount of alcohol was added and the particlecontaining solution was pipetted onto lacy-carbon nickel grids. The samples were examined in a JEOL 2000 FXII TEM operated at $200 \mathrm{kV}$ with a $\mathrm{LaB}_{6}$ filament. The AEM was equipped with a Gatan GIF200 imaging filter, which when operated in spectroscopy mode had an energy resolution of $<1 \mathrm{eV}$. The GIF200 was equipped with a 1k x1k charge coupled device (CCD), which allows imaging at resolutions comparable to photographic film. Electron diffraction patterns were taken with a lower resolution CCD camera. Compositional analysis was performed using an IXRF Iridium II digital pulse processor with an attached Noran Instruments detector.

Electron microprobe analyses were performed using a Cameca SX-50 EMPA. The instrument is equipped with four wavelength dispersive spectrometers and was operated at $20 \mathrm{kV}$ and a beam current of $20 \mathrm{nA}$ measured on a Faraday cage (beam size $\approx 2 \mu \mathrm{m}$ ). Samples and standards were coated with $200 \AA$ of carbon. Synthetic oxides were used as standards for all elements except for $\mathrm{Gd}$ and $\mathrm{Ce}$, which were calibrated with glass standards. Data collection time was $30 \mathrm{~s}$ for most elements and $60 \mathrm{~s}$ for Gd and Zr. Data collection on background positions above and below the peaks was half the time of data collection on respective peak position. The raw data were corrected on-line by the PAP correction procedure [5].

\section{RESULTS}

Pyrochlore accounted for approximately $35-50$ vol\% of all the various $\mathrm{Hf}-\mathrm{Ce}-\mathrm{U}$ ceramic formulations, with the remainder taken up by rutile, brannerite, and zirconolite. The material was fine-grained, with most particles being $<5 \mu \mathrm{m}$ in diameter, except for zirconolite, which occurred as elongated particles, sometimes $>10 \mu \mathrm{m}$ in length. Brannerite was common in the baseline ceramic; however, as impurities were added to the formulation, it became less abundant. Brannerite, ideally $\left[\mathrm{UTi}_{2} \mathrm{O}_{6}\right]$, forms early in the crystallization history, but the addition of impurities as well as the fluxing ability of the added impurities tends to stabilize other phases at the expense of brannerite. Addition of silicon and aluminum resulted in the formation of a calcium alumino-silicate glass and the presence of sodium appeared to lead to formation of perovskite in the ceramic [2].

With SEM X-ray mapping of Hf (Fig. 1), it was possible to determine the distribution of the major phases in the ceramic. Hafnium enriched regions correspond to zirconolite and the $\mathrm{Hf}$-depleted areas mainly to pyrochlore. However, the overall distribution of $\mathrm{Hf}$ as well as the other elements and titanate phases indicated good mixing during formulation of the ceramic pellets. In this paper, we will describe microstructures not observable with SEM that may have important implications for the radiation stability and durability of the ceramics. 


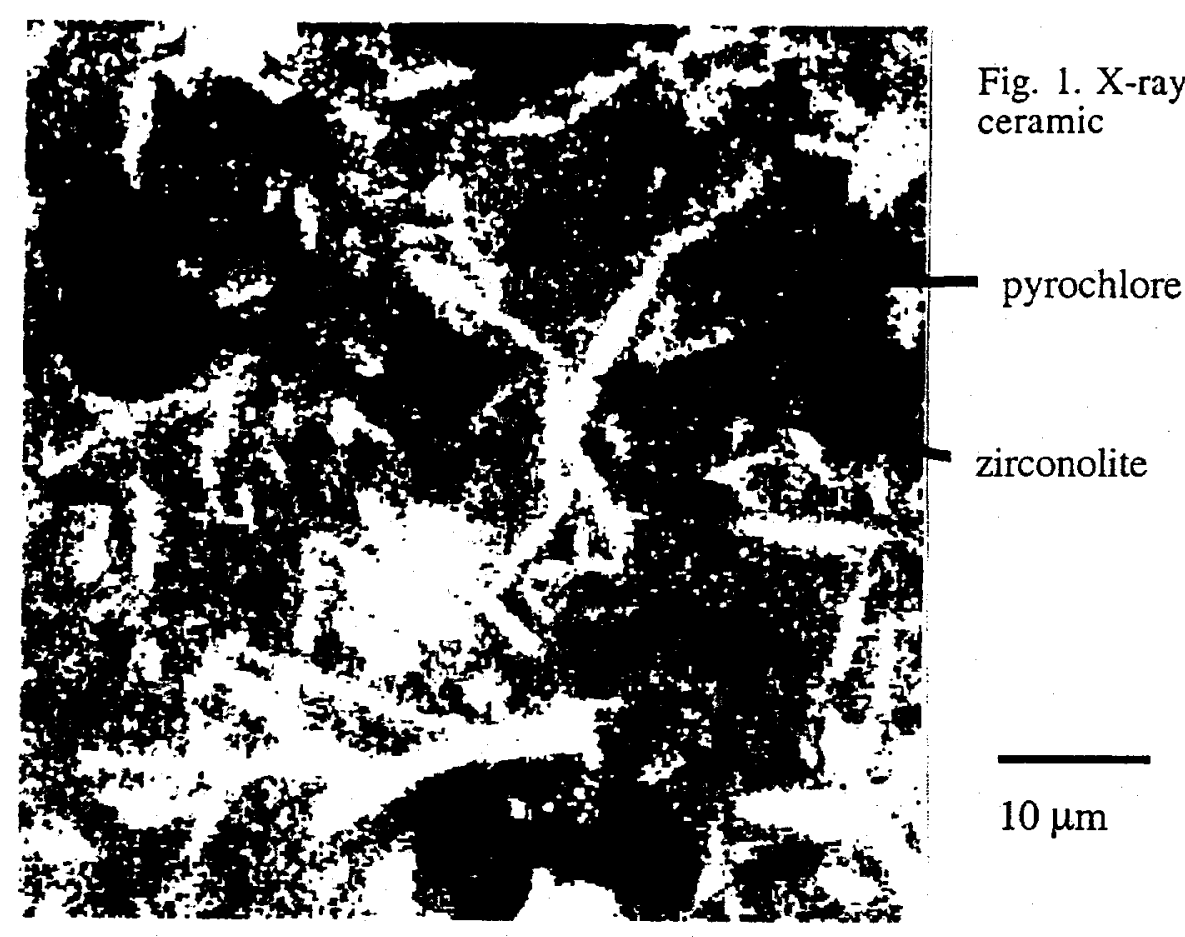

Results from the electron microprobe analyses of the major phases in the baseline are shown in Table 1. The formula totals for zirconolite and pyrochlore are based on 7 oxygens per formula unit, those for brannerite on 6 oxygens per formula unit. In the case of zirconolite, the B-site total is $<1$, suggesting that some of the $\mathrm{Hf}$ and $\mathrm{Zr}$ has been replaced by other elements. Based on crystal chemical considerations, the most likely substituting cation is $\mathrm{U}^{4+}$, as both $\mathrm{Ce}^{3+}$ and $\mathrm{Gd}^{3+}$ are large ions which would more likely exchange with $\mathrm{Ca}$ on the $\mathrm{A}$ site.

In nature, incorporation of $U$ or REE into the $B$ site is hardly ever observed $[6,7]$ but is relatively commonly found in synthetic zirconolites [8]. The data for the baseline zirconolite indicate, however, that even if all $\mathrm{U}$ is accommodated by the $\mathrm{B}$ site, the site total is still $<1$. On the other hand, the total for the Ti site is $>2$, thus suggesting that the $\mathrm{B}$ site additionally contains some $\mathrm{Ti}$, as was also observed in other synthetic zirconolites [9]. Electron energy-loss spectroscopy confirmed that the $\mathrm{Ce}$ in the ceramic is present as $\mathrm{Ce}$ (III) [10]; however, in the plutonium loaded ceramic we may expect different behavior. The $\mathrm{Pu}^{4+}$ ion can be accommodated on the smaller $\mathrm{B}$ site in zirconolite. This is why $\mathrm{Ce}$ is not always a good analog for $\mathrm{Pu}$ in these materials. The data for the baseline ceramic, therefore, are consistent with the following substitutions in zirconolite: $\mathrm{U}^{4+}$ $\Leftrightarrow \mathrm{Zr}^{4+},\left(\mathrm{Ce}^{3+}, \mathrm{Gd}^{3+}\right)+\mathrm{Al}^{3+} \Leftrightarrow \mathrm{Ca}^{2+}+\mathrm{Ti}^{4+}, \mathrm{Ti}^{4+} \Leftrightarrow \mathrm{Zr}^{4+}$, and $\mathrm{Zr}^{4+} \Leftrightarrow \mathrm{Hr}^{4+}$. The microprobe data further reveal that of the three major phases in the ceramic, zirconolite has the highest $\mathrm{Hf} / \mathrm{U}$ and $\mathrm{Gd} / \mathrm{U}$ ratios (see Table 2 ). This demonstrates that uranium is strongly partitioned into brannerite and pyrochlore; the latter, however, are significantly less effective in incorporating $\mathrm{Hf}$ and $\mathrm{Gd}$. These results refer only to the plutonium-free ceramic; we cannot speculate at this time on the possible distribution of neutron absorbers and plutonium in the fully active material. 
Table 1. Electron microprobe analysis of phases in the baseline composition

\begin{tabular}{rlrrr} 
& & pyrochlore & brannerite & zirconolite \\
\hline Oxide $w t \%$ & & & & \\
& $\mathrm{UO}_{2}$ & 26.64 & 36.87 & 9.72 \\
& $\mathrm{CaO}$ & 11.61 & 1.07 & 9.62 \\
& $\mathrm{TiO}_{2}$ & 32.85 & 38.77 & 32.90 \\
$\mathrm{Ce}_{2} \mathrm{O}_{3}$ & 10.50 & 11.81 & 4.95 \\
$\mathrm{Gd}_{2} \mathrm{O}_{3}$ & 9.57 & 6.13 & 7.46 \\
$\mathrm{HfO}_{2}$ & 9.02 & 6.22 & 27.56 \\
$\mathrm{ZrO}_{2}$ & 0.98 & 0.70 & 3.20 \\
& $\mathrm{As}_{2} \mathrm{O}_{3}$ & $\mathrm{NA}$ & $\mathrm{NA}$ & 0.86 \\
$\mathrm{Al}_{2} \mathrm{O}_{3}$ & $\mathrm{NA}$ & $\mathrm{NA}$ & 3.56 \\
\hline & Total & $\mathbf{1 0 1 . 1 5}$ & $\mathbf{1 0 1 . 5 7}$ & $\mathbf{9 9 . 8 4}$
\end{tabular}

Normalized on the basis of:

\begin{tabular}{|c|c|c|c|}
\hline $\begin{array}{l}\text { basis of: } \\
\qquad i \text { Site }\end{array}$ & $0=7$ & $O=6$ & $O=7$ \\
\hline $\mathrm{Ti}$ & 1.91 & 1.95 & 1.80 \\
\hline As & -- & -- & 0.04 \\
\hline $\mathrm{Al}$ & -- & -- & 0.30 \\
\hline Sum & 1.91 & 1.95 & 2.14 \\
\hline$B$ and $A$ Sites & & & \\
\hline Hf & 0.20 & 0.12 & 0.57 \\
\hline $\mathrm{Zr}$ & 0.04 & 0.02 & 0.11 \\
\hline Sum & & & 0.68 \\
\hline$\overline{\mathrm{U}}$ & 0.46 & 0.55 & 0.16 \\
\hline $\mathrm{Ce}$ & 0.30 & 0.29 & 0.13 \\
\hline $\mathrm{Gd}$ & 0.25 & 0.14 & 0.18 \\
\hline $\mathrm{Ca}$ & 0.96 & 0.08 & 0.75 \\
\hline Sum & 2.21 & 1.19 & 1.22 \\
\hline Total Cations & 4.12 & 3.14 & 4.04 \\
\hline
\end{tabular}

$\mathrm{NA}=$ not analyzed. Average relative errors $(2 \sigma): \mathrm{U} 1.2 \%, \mathrm{Ca} 2.5 \%, \mathrm{Ti} 0.6 \%, \mathrm{Ce}$ $2.4 \%, \mathrm{Gd} 4 \%$, $\mathrm{Hf} 1.6 \%, \mathrm{Zr} 2.5 \%, \mathrm{Al} 2 \%$, and $\mathrm{As} 4 \%$.

Table 2. Distribution of Key Elements in the Main Titanate Phases

\begin{tabular}{lccc}
\hline & pyrochlore & brannerite & zirconolite \\
\hline $\mathrm{Hf} / \mathrm{Zr}$ & 5.39 & 5.19 & 5.05 \\
$\mathrm{Hf} / \mathrm{U}$ & 0.43 & 0.22 & 3.64 \\
$\mathrm{Gd} / \mathrm{U}$ & 0.54 & 0.25 & 1.14 \\
$\mathrm{U} / \mathrm{O}$ & 0.07 & 0.09 & 0.02 \\
\hline
\end{tabular}

As Fig. 1 shows, zirconolite tended to form elongated crystals throughout the pyrochlore matrix. In this paper, we concentrate mainly on the interaction between pyrochlore and zirconolite and the microstructures observed within the pyrochlore. These features could not be readily identified with SEM. We will now discuss these microstructural features in pyrochlore and zirconolite in more detail. 
In these ceramics, zirconolite appeared to be present primarily as the $2 \mathrm{M}$ structure type shown by electron diffraction analysis [8]. In many regions, the boundary between the zirconolite and pyrochlore indicated almost no disruption in the lattice between the two phases. The TEM image shown in Fig. 2 reveals a zone of pyrochlore sandwiched between two regions of zirconolite. The zirconolite also exhibited extensive sub-micron zoning. Transition metals, REE, and ACT are not distributed uniformly throughout the zirconolite but are concentrated in extended defects, which can lead to the formation of zirconolite polytypes [8].

The (001) planes of this zirconolite-2M are preferentially oriented parallel to (111) of pyrochlore. Figure 2 shows that the interface between pyrochlore and zirconolite is completely continuous, suggesting a perfect lattice match and thus demonstrating the close structural relationship between the two phases.

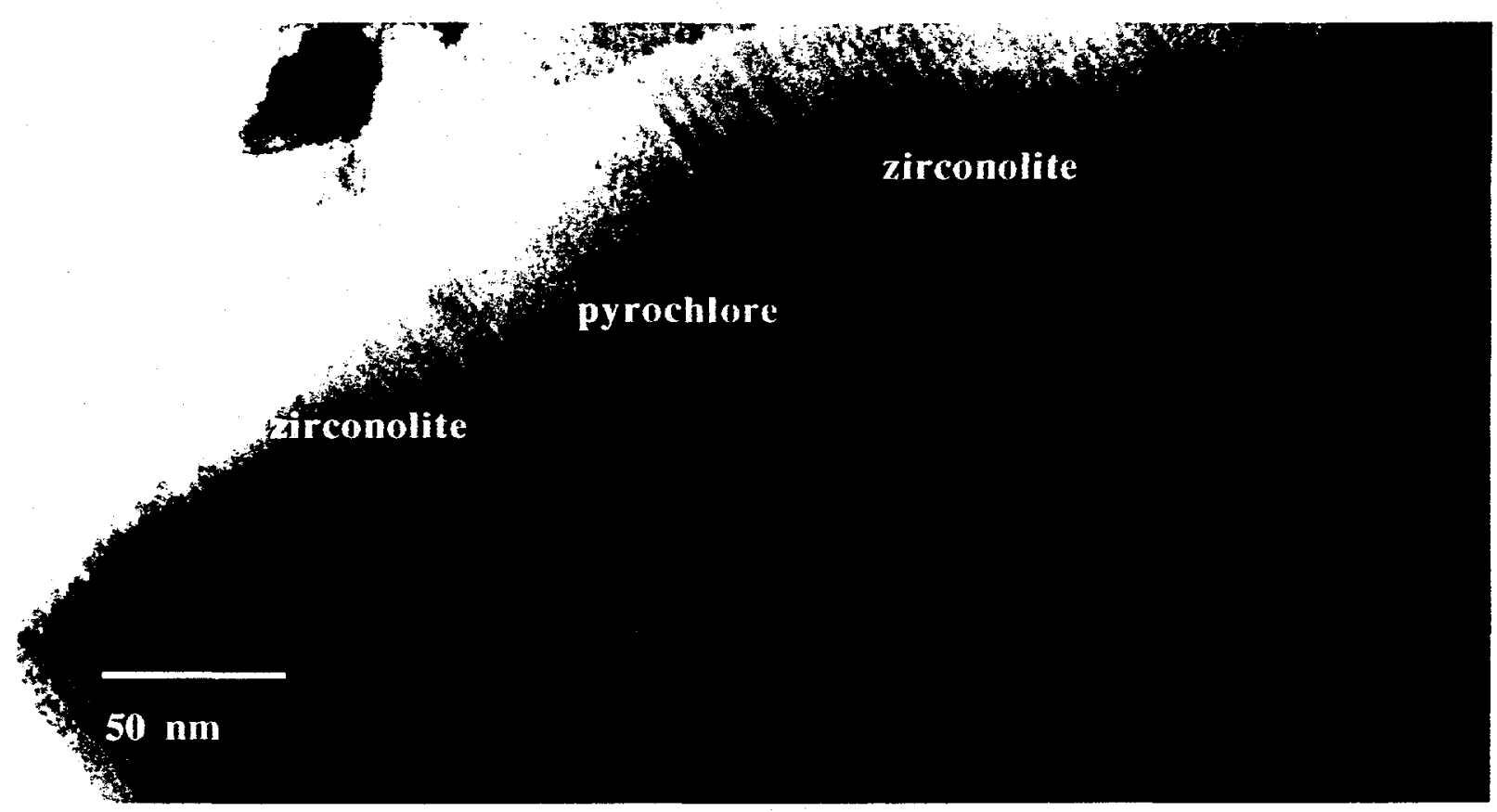

Figure 2. Transmission electron microscopy image of pyrochlore and zirconolite in the baseline ceramic. Note the continuity in the structure between the zirconolite and pyrochlore zones and the stacking disorder in the zirconolite.

In Figs. $3 \mathrm{a}$ and $3 \mathrm{~b}$, diffraction patterns of pyrochlore and zirconolite-2M are shown. The $d_{111}$ spacing in pyrochlore is similar to the $d_{002}$ spacing in zirconolite. The TEM multibeam image of pyrochlore taken along B[110] axis is shown in Fig. 4a. However, when we inspected the pyrochlore grains individually, we found lamellae within the grains (see Fig. $4 \mathrm{~b}$ and $4 \mathrm{c}$ ); $\mathrm{x}$-ray analysis suggested that these possessed a zirconolite-like composition. The lamellae were observed in all the samples examined, including those from the baseline, the extreme oxide impurity sample, and the metallic impurity sample. The lamellae may possibly be of the zirconolite-4M type and, in the Pufree ceramic, are always enriched in $\mathrm{Hf}$ and depleted in $\mathrm{U}$ relative to the surrounding pyrochlore (see Fig. 5). The EDS analysis confirmed that the lamellae are depleted in U and enriched in Hf. More convincing evidence comes from the energy-filtered images of the lamellae. 


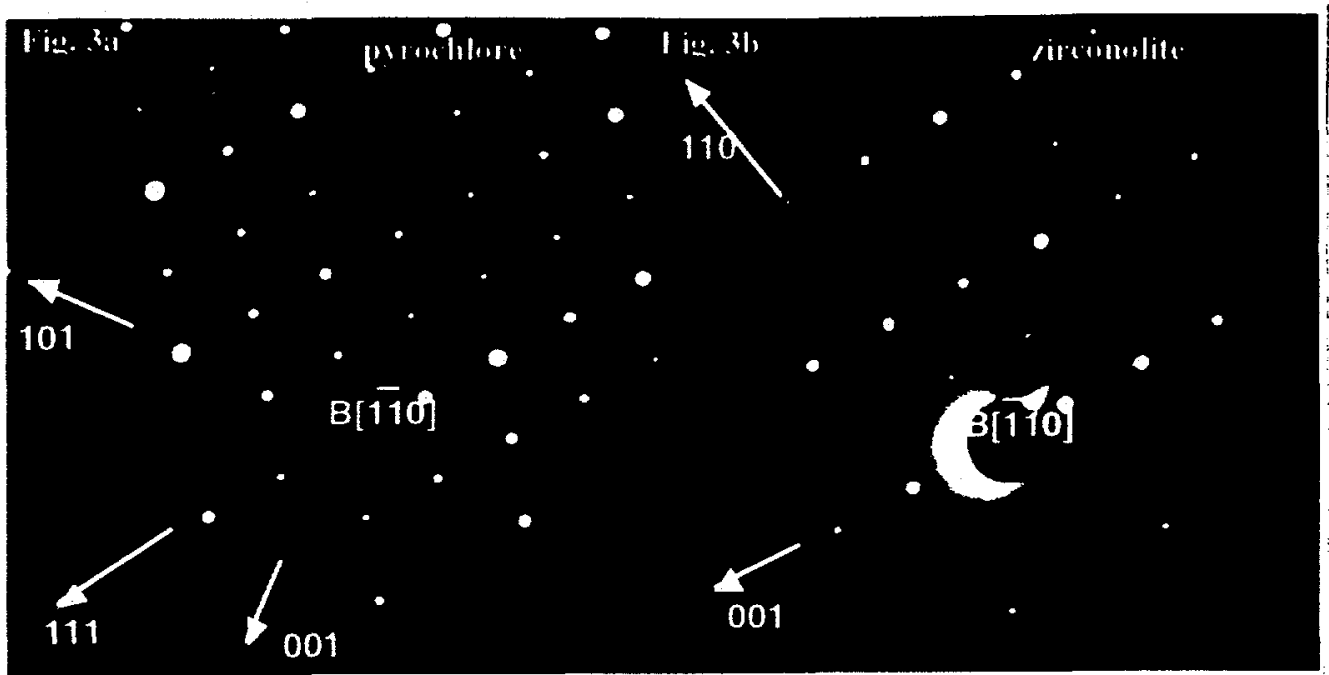

Figure 3. Electron diffraction patterns from neighboring grains of (a) pyrochlore and (b) zirconolite. The (001) systematic row of zirconolite has an almost identical spacing to the (111) systematic row in the pyrochlore, demonstrating the close structural similarities these two phases share.

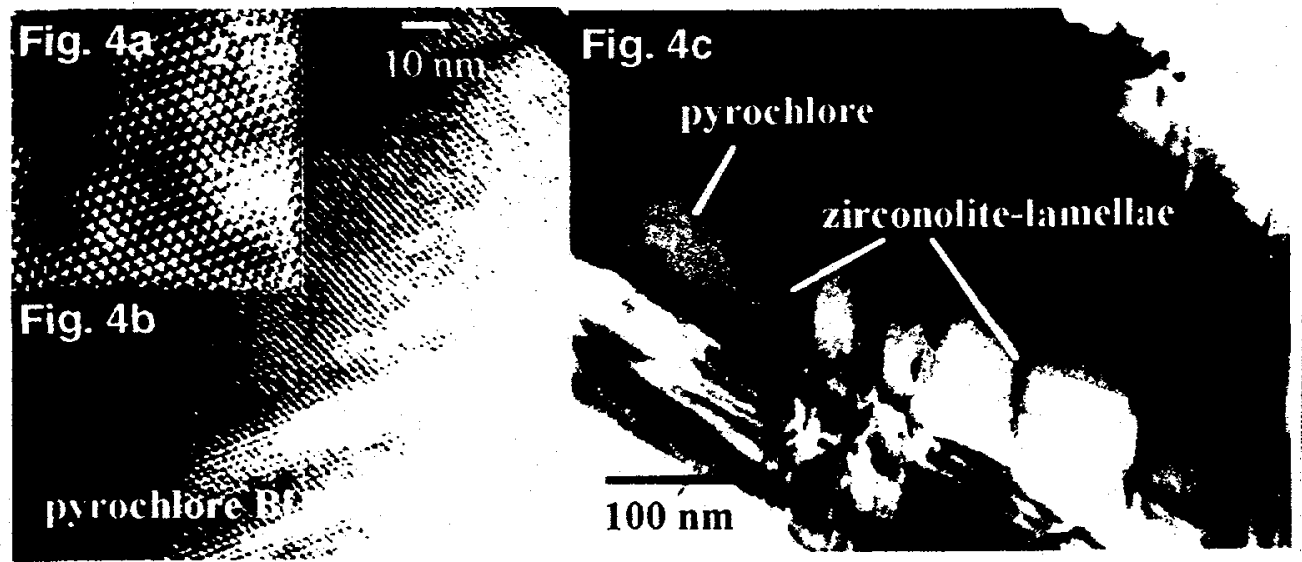

Figure 4. (a) and (b) Multibeam images of the pyrochlore showing lamellae, and (c) bright-field image of zirconolite-like lamellae structures within pyrochlore.

The energy filtered image (Fig. 6) suggests that the zirconolite lamellae are significantly depleted in uranium relative to the host pyrochlore. If this behavior is mirrored in the plutonium ceramic, then one will expect different metamictization rates for the two phases. However, as the lamellae are very thin $(10-40 \mathrm{~nm}), \alpha$-recoil events originating from the pyrochlore matrix would result in amorphization not only of pyrochlore but also of the enclosed zirconolite lamellae. 

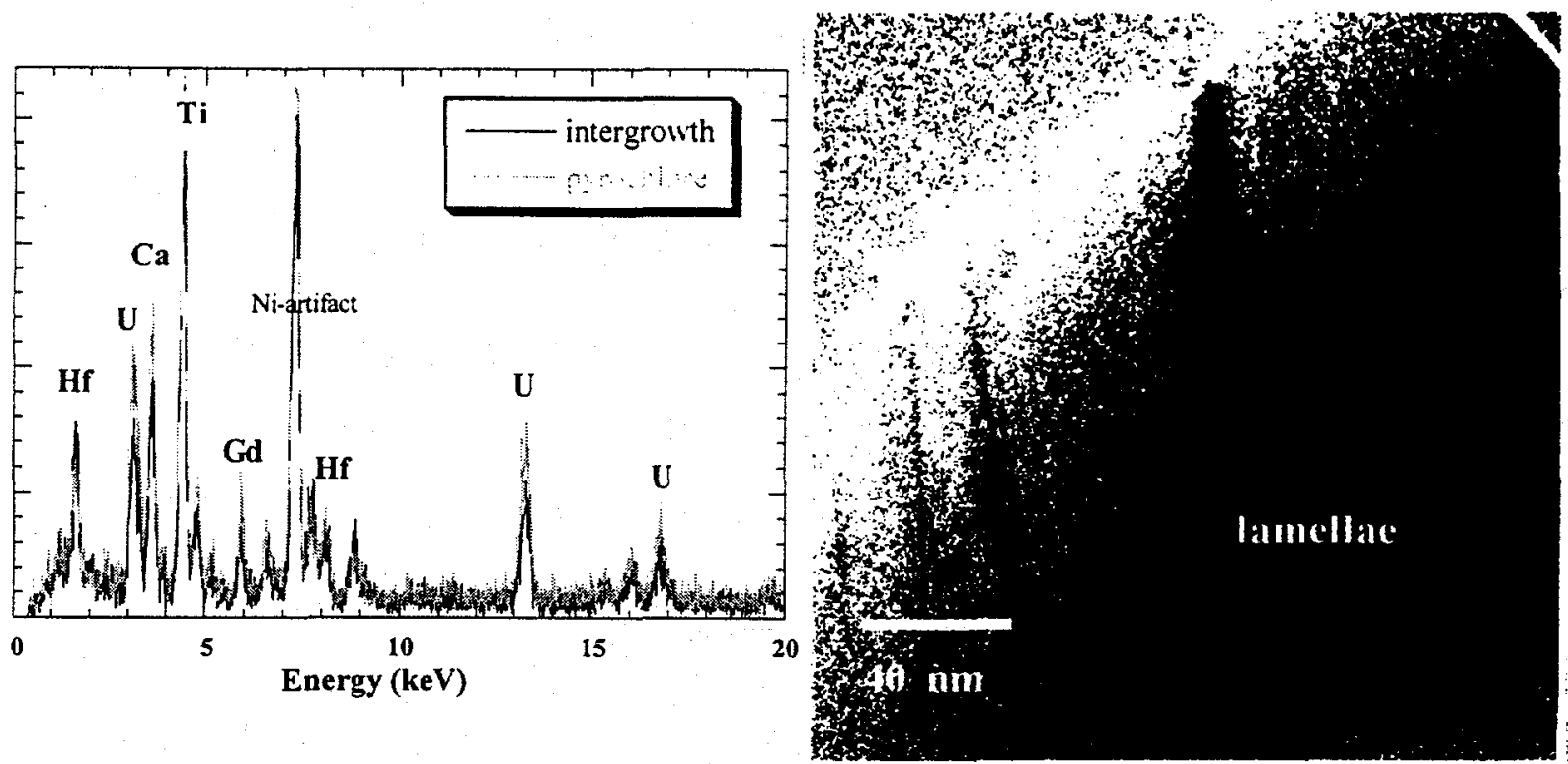

Figure 5. X-ray energy dispersive spectra of pyrochlore and the enclosed zirconolite-type lamellae.

Figure 6. Energy-filtered TEM image of the $\mathrm{U}$ distribution in pyrochlore from a metallic impurity ceramic which indicates that the lamellae are deficient in $\mathrm{U}$.

\section{DISCUSSION}

As zirconolite may be considered a derivative of the cubic pyrochlore structure, the intergrowth of these two phases in the ceramic is not surprising. However, it is possible that these lamellae are formed as a result of the large amounts of Hf introduced into the formulation of the titanate ceramic: the small $\mathrm{Hf}$ ion $(\mathrm{r}[\mathrm{VIII}]=83 \mathrm{pm})$ is more easily accommodated by the 7 -fold coordinated B site in zirconolite than by the large 8 -fold coordinated A site in pyrochlore. Although these zirconolite lamellae were observed in the Hf-rich system, similar behavior will most likely occur in $\mathrm{Zr}$-bearing ceramics, as $\mathrm{Zr}$ and $\mathrm{Hf}$ have virtually indistinguishable chemistries.

Recent work by Putnam et al. [11], however, revealed differences in the formation energies of $\mathrm{Zr}$ - and $\mathrm{Hf}$-bearing zirconolites. Further investigation of differences in $\mathrm{Hf}$ and $\mathrm{Zr}$ behavior in these systems might be revealing. The presence of zirconolite lamellae on the $\{111\}$ planes in pyrochlore suggests that they may have formed through exsolution during the cool down from the sintering temperature. Analysis of the interface between pyrochlore and zirconolite failed to detect any evidence for diffusion profiles near the boundaries. Therefore, it is not clear at the current stage whether these zirconolite lamellae are real exsolution lamellae or, alternatively, represent a growth feature which might have formed during the sintering process rather than during the cooling.

The lamellae in the pyrochlore are extremely small relative to the neutron penetration distances, estimated to be several centimeters, but are approximately equal to the distance traversed by an $\alpha$-recoil $(10-20 \mathrm{~nm})$ [12]. This implies that although much of the Hf may be segregated into a distinct phase, its capacity to absorb neutrons will not be diminished. In addition, we might expect that despite having possibly lower concentrations of plutonium in the lamellae, these features will be made metamict from the radioactive decay of plutonium in the neighboring pyrochlore. During any simulated radiation damage investigations of this material, these types of effects need to be evaluated. In 
particular, do the lamellae-pyrochlore boundaries offer regions where micro-fractures can develop during radiation induced swelling? Based on current loading expectations for plutonium in the fully active ceramic, significant damage with partial metamictization is expected by 1000 years $\left(\approx 9.7 \times 10^{15} \alpha / \mathrm{mg}\right)$. Natural zirconolites and pyrochlores exhibit a significant degree of amorphization at such doses $[12,13]$. If micro-fracturing develops from radiation-induced expansion, this may offer potential pathways for fluids that could lead to enhanced ceramic dissolution rates, should all other barriers fail.

\section{CONCLUSIONS}

It is concluded that the introduction of significant amounts of hafnium may be responsible for the presence of zirconolite-2M crystals in the ceramic and could also lead to formation of zirconolite intergrowths within the pyrochlore. We would also expect the same process to occur with $\mathrm{Zr}$-loaded ceramic materials. The presence of zirconolite lamellae within pyrochlore suggests that the volume expansion due to radiation damage in cubic pyrochlore will not be isotropic. However, as the lamellae grow epitaxially on the $\{111\}$ planes in pyrochlore, there should be no change in the isotropic expansion behavior of the material.

\section{ACKNOWLEDGMENTS}

This work was performed under guidance of the Fissile Materials Disposition Project (FMD). Work supported by the U.S. Department of Energy under contract W31-109-ENG-38.

\section{REFERENCES}

1. E. R. Vance, C. J. Ball, R. A. Day, K. L. Smith, M. G. Blackford, B. Begg, and P. J. Angel, J. Alloys Comp. 213/214 (1994) 406-409.

2. A. J. Bakel, C. J. Mertz, E. C. Buck, D. B. Chamberlain, in Scientific Basis for Nuclear Waste Management XXII Conf., Boston, MA, Nov 30-Dec 4 (1998).

3. V. F. Sears, Neutron News 3 (1992) 29-37

4. F. A. Cotton and G. Wilkinson, Advanced Inorganic Chemistry, John Wiley \& Sons, New York, 1980, 4th ed., pp. 824-827.

5. J. L.Pouchou and F. Pichoir, Rech. Aérosp 1984-3 (1984) 167-192.

6. G. R. Lumpkin, K. L. Smith, and R. Gieré, Micron 28 (1997) 57-68.

7. R. Gieré, C. T.Williams, and G. R. Lumpkin, Schweizerische Mineralogische und Petrographische Mitteilungen 78 (1998) 433-459.

8. K. L. Smith and G. R. Lumpkin, in Defects and Processes in the Solid State: Geoscience Applications, McLaren Volume, ed., J. N. Boland and J. D. FitzGerald, Elsevier Science Publishers (1993).

9. B. M. Gatehouse, I. E. Grey, R. J. Hill, H. J. Rossell H, Acta Cryst B37 (1981) 306-312.

10. J. A. Fortner and E. C. Buck, Appl. Phys. Lett. 68 (1996) 3819-3821.

11. R. L. Putnam, A. Navrotsky, J. Boerio-Goates, and B. F. Woodfield, in Scientific Basis for Nuclear Waste Management XXII Conf., Boston, MA, Nov 30-Dec 4 (1998).

12. R. C. Ewing, W. J. Weber, Prog. Nucl. Energy 29 (1995) 63-127.

13. G. R. Lumpkin, K. P. Hart, P. J. McGlinn, T. E. Payne, R. Gieré, and C. T. Williams, Radiochim. Acta 66/67 (1994) 469-474. 